\title{
KINETIC STUDY OF SYNTHESIS REACTION OF LIGNOSULFONATE USING ISOTHERMAL DIFFERENTIAL SCANNING CALORIMETRY METHOD
}

\author{
Nguyen Truong Giang1, , Tran Trung Kien ${ }^{2}$, Nguyen Thi Hoa ${ }^{2}$, Pham Van Thiem ${ }^{2}$ \\ ${ }^{1}$ National University of Civil Engineering (NUCE), 55 Giai Phong, Hanoi \\ ${ }^{2}$ School of Chemical Engineering, Hanoi University of Science and Technology (HUST), \\ 1 Dai Co Viet, Hanoi \\ *Email: truonggiangnuce@gmail.com
}

Received: 18 December 2016; Accepted for publication: 28 February 2017

\begin{abstract}
The kinetics of lignin methylsulfonation in solution were studied by using differential scanning calorimetry (DSC) technique under an isothermal program, at 55, 65, 75 and $85{ }^{\circ} \mathrm{C}$. It was found that the activation energy of the process was $E_{\alpha}=41.26 \mathrm{~kJ} / \mathrm{mol}$, and the preexponential factor A was $1.85 \times 10^{3} \mathrm{~s}^{-1}$.
\end{abstract}

Keywords: lignin, lignosulfonat, methylsulfonation, isothermal DSC.

\section{INTRODUCTION}

Sulfonated lignins are polymers of phenylpropane with methoxyl groups that exhibit polyelectrolyte behavior in an aqueous solution and are very stable chemically. The properties of sulfonated lignins can vary depending on the molecular weights and molecular weight distribution, which is analogous to the distribution of the polymerization degree or chain length; the sulfonation degree; and the purity of the product [1].

Lignosulfonates are widely used in many fields of industry, e.g. as dispersants in cement and kaolinite; as adsorbents on kaolinite and calcium carbonate to produce modified fillers for composites and papermaking, as flocculants for textile industry, etc. [2]. Synthesis of lignosulfonates by the two step process as presented in our previous study [3] showed many advantages such as high efficiency, smoothly reaction mode, shorter reaction time and lower reaction temperature.

Several literature studies have been studied on the kinetics of lignin methylolation. In 1988, Gardner and Moginnis studied the methylolation rate and kinetic parameters of kraft lignin and steam-exploded lignin by monitoring the rate of formaldehyde disappearance. These authors postulated the reaction of phenol molecules of lignin with formaldehyde as a second-order reaction [4]. In 1993, Peng et al. studied the kinetics of lignin methylolation (in production of 
ammonium-based lignosulfonate (ALS) and sodium-based lignosulfonate (SLS)) in solution by monitoring the rate of formaldehyde disappearance and by using differential scanning calorimetry (DSC) technique [5]. They found that the methylolation of ALS and SLS had a lower activation energy and a lower preexponential factor than that of phenol.

However, up to date, no similar studies have been reported in determination of kinetics of synthesis reaction of lignosulfonates via using sulfite and fomaldehyde as reagents.

The methods used to study the methylsulfonation kinetics can be classified into mechanistic or phenomenological terms. Mechanistic models are developed from the balance of chemical species involved in the chemical reaction. In most cases, it is difficult to derive a mechanistic model because of the complexity of the methylsulfonation reaction. Thus, phenomenological or empirical models are preferred to study the methylsulfonation kinetics of these polymers [6]. Traditionally, kinetic parameters were calculated from isothermal data by DSC.

The aim of this study was to study the kinetics of sodium-based lignosulfonate forrmation, with the reaction of the functional groups in lignins with other reagents produced by reaction of sodium sulfite and formadehyde, by isothermal DSC technique. The study of the reaction kinetics contributes both to a better knowledge of the process development and to improving the quality of the final product as well.

\section{MATERIALS AND METHODS}

\subsection{Materials}

Lignin: extracted from black liquor by the pulping and papermaking processes of Vietnam Paper Cooperation (Phu Ninh district, Phu Tho province). This black liquor was cooked by alkaline method with Eucalyptus and Acacia melaleuca wood as feedstocks.

Sodium sulfite and formaldehyde: for the methyl sulfonation process.

Pure chemicals for lignin separation and LS synthesis were made in Vietnam and China.

\subsection{Methods}

\subsubsection{Sample preparation}

Sodium sulfite $(3.2 \mathrm{~g})$ reacted with formaldehyde $(0.8 \mathrm{~g})$ to produce the $\mathrm{CH}_{2}(\mathrm{OH}) \mathrm{SO}_{3} \mathrm{Na}$ agent in liquid, at room temperature. Lignin, $1 \mathrm{~g}$, was dissolved in the agent solution. This solution was kept at room temperature with continuous stirring.

\subsubsection{DSC measurements}

The reaction of lignin methylsulfonation can proceed over a wide temperature range. In order to study the isothermal reaction of thermoset systems, the first step was the selection of appropriate isothermal reaction temperatures, by analysing nonisothermal reaction DSC curves [7].

The calorimetric measurements were performed with a differential scanning calorimeter. The isothermal reaction kinetics of the present system was studied with a Seteram DSC 131 instrument operated in nitrogen atmosphere using aluminium pans. An empty pan and pure indium were used as the reference and standard for calorimeter calibration, 
respectively. The reaction was carried out at several temperatures of $55,65,75$, and $85{ }^{\circ} \mathrm{C}$ according to the dynamic DSC results. After the sample pan was settled, the temperature was raised rapidly to a specified value at $10{ }^{\circ} \mathrm{C} / \mathrm{min}$. The heat flow was recorded as a function of the reaction time. The total heat of the reaction $\Delta \mathrm{H}$ was determined from the non-isothermal DSC curve at $10^{\circ} \mathrm{C} / \mathrm{min}$.

\subsubsection{Reaction kinetic models}

The reaction rate equation utilized to study the kinetics of methylsulfonation can be expressed, in general, as:

$$
\frac{\mathrm{d} \alpha}{\mathrm{dt}}=\mathrm{k}(\mathrm{T}) \mathrm{f}(\alpha)
$$

where, $\alpha$ and $\mathrm{t}$ are extent of conversion (\%) and time of reaction (s), respectively, $\mathrm{k}(\mathrm{T})$ is reaction rate constant $\left(\mathrm{s}^{-1}\right)$ and $f(\alpha)$ is a function describing the reactant concentration and is assumed to be independent from temperature. If a process is accompanied by release or absorption of heat, the extent of conversion is evaluated through the fraction of the total heat released or absorbed in the process. In this case, $\alpha$ increases from 0 to 1 as the process progresses from initiation to completion. It must be kept in mind that the physical properties measured by the thermal analysis methods are not species-specific and, thus, usually cannot be linked directly to specific reactions of molecules. For this reason, the value of $\alpha$ typically reflects the progress of the overall transformation of a reactant to products [8].

The temperature dependence of the conversion rate is assumed to reside in the constant (k) through the Arrhenius equation:

$$
\mathrm{k}(\mathrm{T})=\mathrm{A} \exp \left(\frac{-\mathrm{E}}{\mathrm{RT}}\right)
$$

where, A is preexponential factor $\left(\mathrm{s}^{-1}\right), \mathrm{E}$ is activation energy $(\mathrm{J} / \mathrm{mol}), \mathrm{R}$ is gas constant $(\mathrm{J} / \mathrm{mol} . \mathrm{K})$, and $\mathrm{T}$ is reaction temperature $(\mathrm{K})$.

Although there is a significant number of reaction models, they all can be reduced to three major types: accelerating, decelerating, and sigmoidal (sometimes also called autocatalytic). Each of these types has a characteristic "reaction profile" or "kinetic curve", the terms frequently used to describe a dependence of $\alpha$ or $\mathrm{d} \alpha / \mathrm{dt}$ on $\mathrm{t}$ or $\mathrm{T}$. Such profiles are readily recognized for isothermal data because in this case $\mathrm{k}(\mathrm{T})=$ const in Eq. (2) so that the kinetic curve shape is determined by the reaction model alone.

From the experimental heat flow rate profiles, the conversion and reaction rate profiles were obtained using the following equations [7]:

$$
\begin{gathered}
\alpha=\frac{\Delta \mathrm{H}_{\mathrm{t}}}{\Delta \mathrm{H}_{\mathrm{Tot}}} \quad(0 \leq \alpha \leq 1) \\
\frac{\mathrm{d} \alpha}{\mathrm{dt}}=\left(\frac{1}{\Delta \mathrm{H}_{\mathrm{Tot}}}\right) \cdot\left(\frac{\mathrm{d} \Delta \mathrm{H}_{\mathrm{t}}}{\mathrm{dt}}\right)
\end{gathered}
$$

where, $\mathrm{H}_{\mathrm{t}}$ is heat flow $(\mathrm{J} / \mathrm{g})$ and $\Delta \mathrm{H}_{\mathrm{Tot}}$ is total enthalpy of reaction. Enthalpies were measured by integrating the heat flow rate $\left(\mathrm{d} \Delta \mathrm{H}_{t} / \mathrm{dt}\right)$ against time curves in the case of DSC measurements. 
Isothermal kinetic data can be modelled using mechanistic models to describe the reaction kinetics.

The function $\mathrm{f}(\alpha)$ for an $n^{\text {th }}$ - order reaction has the following form [9]:

$$
f(\alpha)=(1-\alpha)^{\mathrm{n}}
$$

where $\mathrm{n}$ is reaction order. Systems obeying $n^{\text {th }}$ - order reaction kinetics will obviously have the maximum reaction rate at $\mathrm{t}=0$. For an $n^{\text {th }}$-order reaction, the conversion rate is given by:

$$
\frac{\mathrm{d} \alpha}{\mathrm{dt}}=\mathrm{k}(1-\alpha)^{\mathrm{n}}=\mathrm{A} \exp \left(-\frac{\mathrm{E}}{\mathrm{RT}}\right)(1-\alpha)^{\mathrm{n}}
$$

To model the reaction process, the values of $\mathrm{n}, \mathrm{A}$, and $\mathrm{E}$ need to be determined. At an isothermal condition these three parameters can be obtained through a two-step linear regression analysis, using transformed eqs. (2) and (6). Writing Eq. (6) in the logarithmic form for different isothermal temperatures:

$$
\begin{aligned}
& \ln \mathrm{k}=\ln \mathrm{A}-\frac{\mathrm{E}}{\mathrm{RT}} \\
& \ln \left(\frac{\mathrm{d} \alpha}{\mathrm{dt}}\right)=\ln \mathrm{k}+\mathrm{n} \ln (1-\alpha)=\ln \mathrm{A}-\frac{\mathrm{E}}{\mathrm{RT}}+\mathrm{n} \ln (1-\alpha)
\end{aligned}
$$

where $\ln$ represents natural logarithm. According to Eq. (8), the apparent activation energy, $\mathrm{E}_{\alpha}$, and the constant $\ln \mathrm{A}$ can be obtained, respectively, from the slope and the intercept of the linear relationship of lnk against 1/T for a constant conversion.

\section{RESULTS AND DISCUSION}

\subsection{DSC measurements}

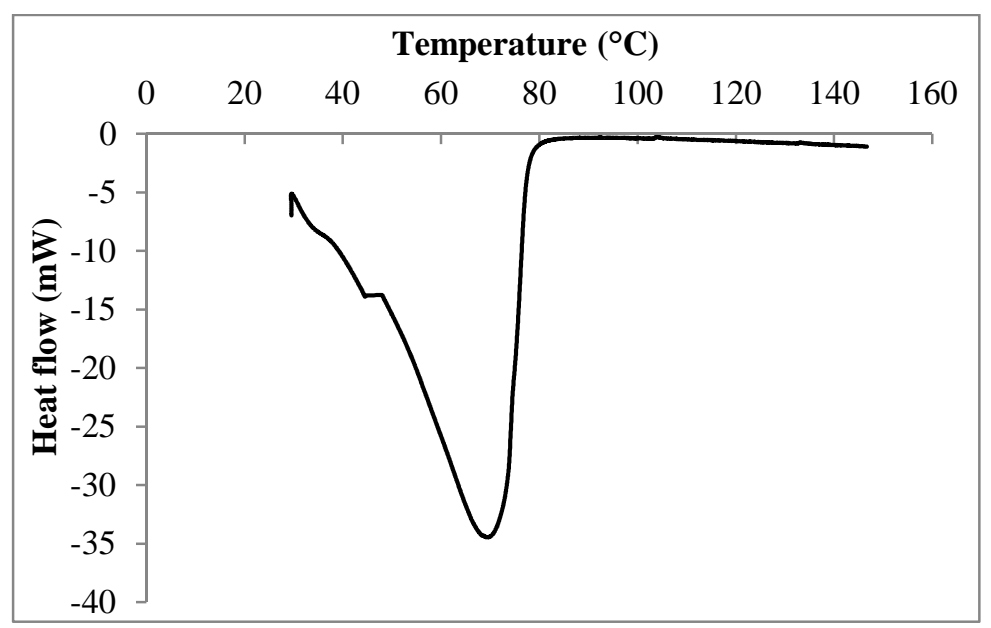

Figure 1. Non-isothermal DSC curver from methylsulfonation of lignin at heating rate of $1 \mathrm{~K} / \mathrm{min}$.

Typical nonisothermal DSC curve displaying heat flow rate against temperature for systems was shown in Fig. 1. The information which could be obtained directly from the DSC curve included the temperature that the reaction started, the peak temperature, the 
terminal temperature, and the values of enthalpy.

In fact, strictly isothermal experiments were not possible, because there was always a finite non-isothermal heat-up time. At low reaction temperature, the reaction rate was slow and the corresponding heat flow rate might not exceed the baseline noise. At high reaction temperature, the reaction rate was fast, which meat a significant degree of conversion was reached before the isothermal regime was set [8].

Figure 2 showed the isothermal reaction curves for methylsulfonation of lignin obtained at the different operating temperatures $\left(55,65,75\right.$ and $\left.85{ }^{\circ} \mathrm{C}\right)$. This was an endothermic reaction.

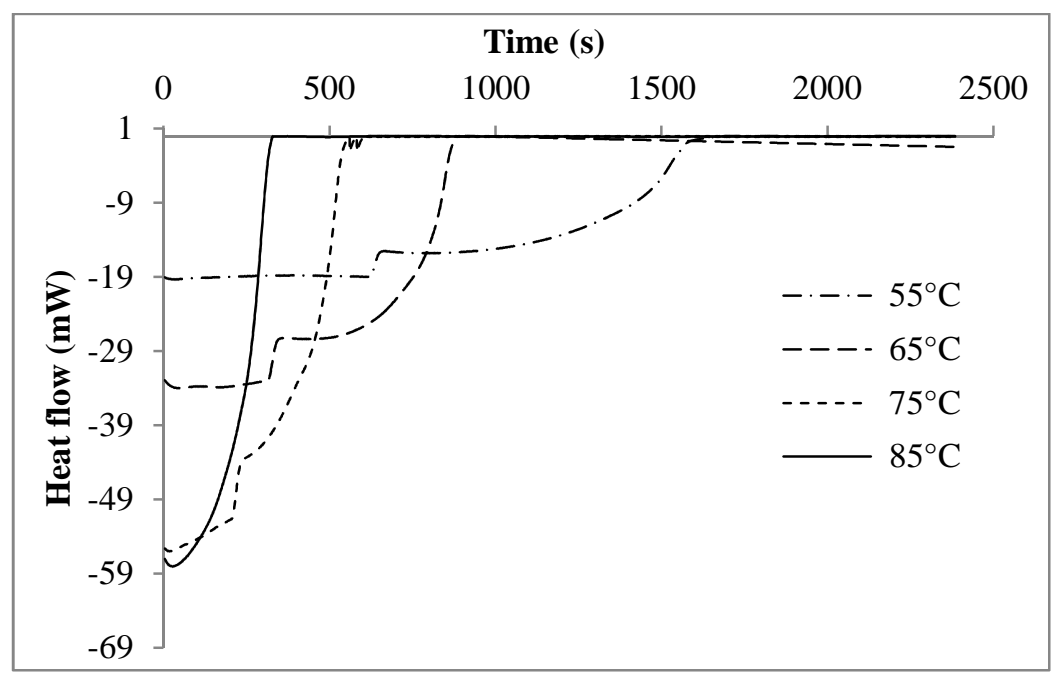

Figure 2. Isothermal DSC curves from methylsulfonation of lignin at different temperatures.

An isothermal calorimetric experiment, such as DSC, immediately showed to which type the $\mathrm{n}^{\text {th }}$-order or autocatalytic reaction belonged. This was due to the fact that under isothermal conditions, the $\mathrm{n}^{\text {th }}$-order reaction presented its maximum heat release rate at the beginning of exposure to initial temperature, whereas the autocatalytic reaction presented no heat release rate at this time [10]. In this study, under the isothermal condition (Fig. 2), the heat flow rate was highest when $\mathrm{t}=0$, and then decreased with increasing reaction time. Apparently, methylsulfonation of lignin followed a $n^{\text {th }}$-order reaction mechanism.

\subsection{Determination of kinetic parameters}

The recorded curves were used to calculate the conversion versus time data subsequently used for kinetic analysis.

A series of isothermal reaction rate curves, as a function of reaction time for methylsulfonation of lignin were shown in Figure 3.

From the shapes of the reaction curves (Fig. 3), we could see that after an induced period, the conversion rate increased rapidly (acceleration period), followed by a progressive slowing down (deceleration period) until the reaction curve reached approximately a plateau corresponding to the maximum value of the degree of cure at all temperatures. As expected, the maximum degree of cure increased with the increase of temperature. 


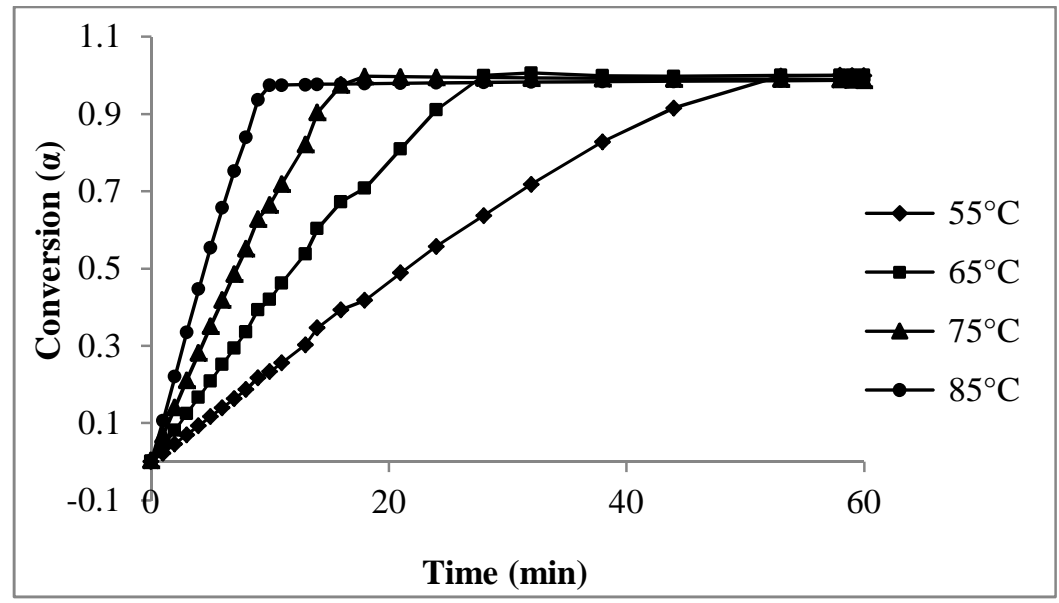

Figure 3. The differential conversion curves $\alpha$ vs t obtained for the isothermal methylsulfonation process of lignin at different operating temperatures.

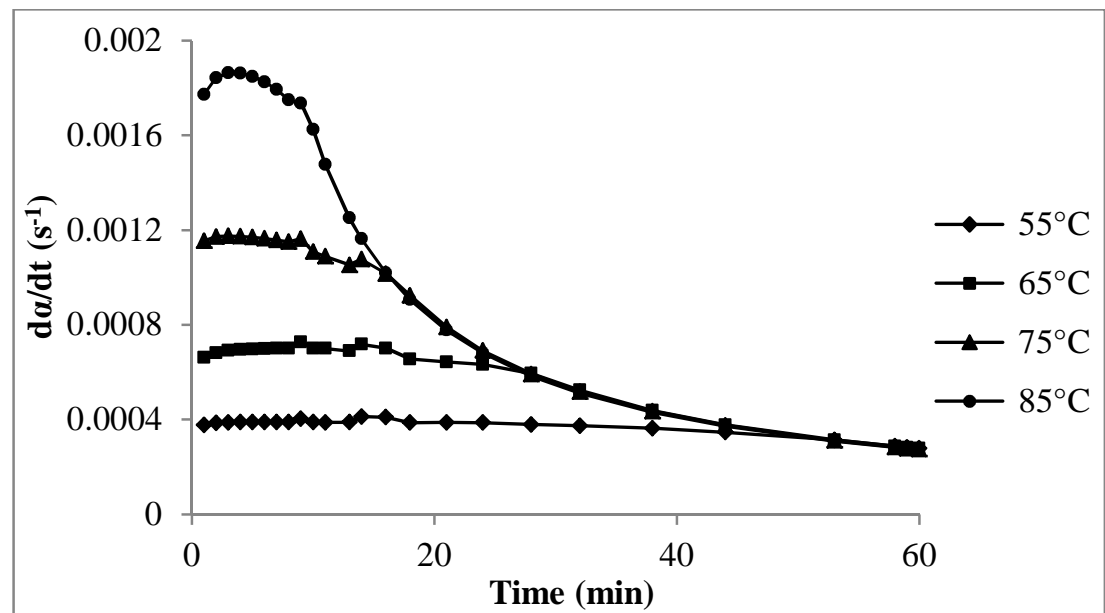

Figure 4. The differential reaction rate curves (d $\alpha / \mathrm{dt}$ vs $\mathrm{t}$ ) obtained for the isothermal methylsulfonation process of lignin at different operating temperatures.

Figure 4 showed the differential reaction rate curves obtained for the isothermal reaction process at different operating temperatures. At higher temperatures, reaction times were lower. As shown in Fig. 4, the conversion rate peak became higher and shifted to shorter times when the temperature increased.

It could be easily seen from the curves that the value of the peak at $t=0$ for the methylsulfonation reaction was increased, and the time needed for the methylsulfonation reaction to reach the endpoint was shorter with increasing temperature. At $55^{\circ} \mathrm{C}$, the whole time for the methylsulfonation was about $50 \mathrm{~min}$., while only several minutes were needed at $85^{\circ} \mathrm{C}$.

The continuous values obtained by the sigmoidal equation have enabled us to determine the kinetic parameters for modelling the reaction. 


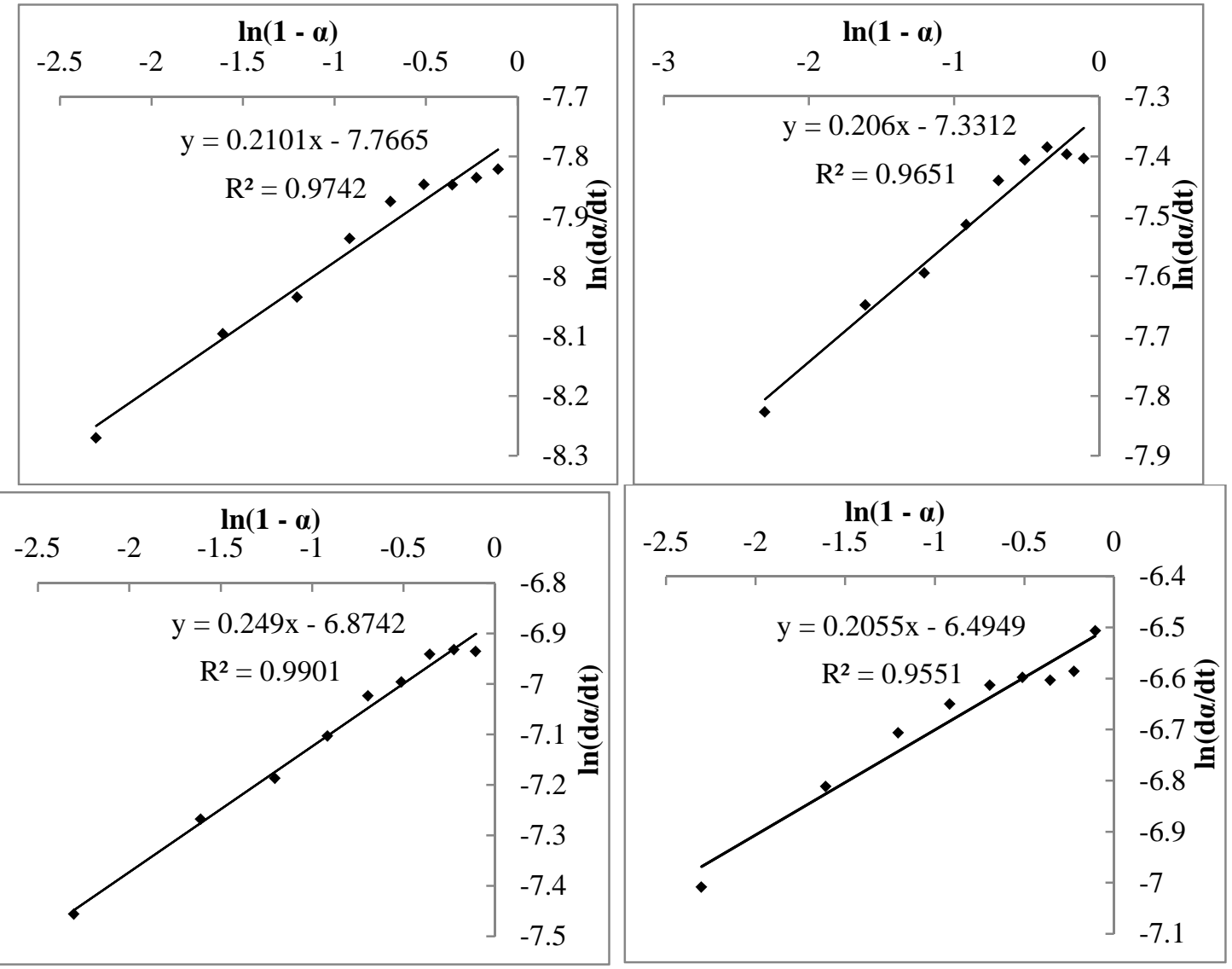

Figure 5. The plots of $\ln (1-\alpha)$ vs. $\ln (\alpha)$ at different temperatures, respectively:

(a) $55^{\circ} \mathrm{C}$; (b) $65^{\circ} \mathrm{C}$; (c) $75^{\circ} \mathrm{C}$; (d) $85^{\circ} \mathrm{C}$.

Table 2. $\mathrm{n}$ and lnk calculated from isothermal DSC data.

\begin{tabular}{|c|c|c|c|c|}
\hline Temperature $\left({ }^{\circ} \mathrm{C}\right)$ & 55 & 65 & 74 & 85 \\
\hline $\mathrm{n}$ & 0.2101 & 0.206 & 0.249 & 0.2055 \\
\hline $\operatorname{lnk}$ & -7.7665 & -7.3312 & -6.8742 & -6.4949 \\
\hline
\end{tabular}

Table 3. Reaction kinetic parameters of methylsulfonation of lignin under isothermal temperatures.

\begin{tabular}{|c|c|c|c|}
\hline \multirow{2}{*}{ Temperature $\left({ }^{\circ} \mathrm{C}\right)$} & \multicolumn{3}{|c|}{ Model parameter } \\
\cline { 2 - 4 } & Reaction order, $\mathrm{n}$ & $\begin{array}{c}\text { Reaction rate constant, } \mathrm{k} \\
\left(10^{-3}\right)\left(\mathrm{s}^{-1}\right)\end{array}$ & $\begin{array}{c}\text { Correlation coefficient } \\
\mathrm{r}^{\mathrm{a}}\end{array}$ \\
\hline 55 & 0.21 & 4.2 & 0.97 \\
\hline 65 & 0.2 & 6.5 & 0.96 \\
\hline 75 & 0.25 & 10.3 & 0.99 \\
\hline 85 & 0.2 & 15.1 & 0.95 \\
\hline
\end{tabular}


The isothermal DSC data were used to calculate the kinetic parameters $\mathrm{k}$ and $\mathrm{n}$ according to eq. (7). Figure 5 showed plots of $\ln (1-\alpha)$ vs. $\ln (\alpha)$ at different temperatures. Reaction orders (n) were determined by slope of plots and the values lnk determined by constant of linear relationship. The results were shown in Table 3. From Table 3, the mean cure reaction order was about 0.21 .

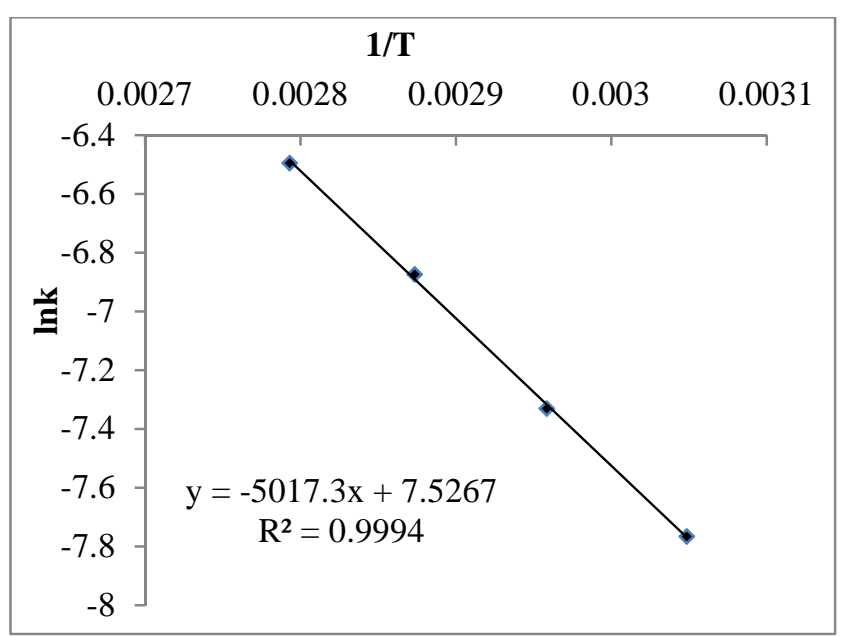

Figure 6. The Arrhenius-type plot (lnk vs. 1/T) evaluated for the methylsulfonation of lignin under isothermal conditions.

$\mathrm{E}_{\alpha}$ and the constant $\ln \mathrm{A}$ could be obtained from the slope of the linear relationship of lnk against $1 / \mathrm{T}$. Figure 6 . showed plot (lnk vs. $1 / \mathrm{T}$ ) evaluated for the methylsulfonation of lignin under isothermal conditions. Analysis with eq. (7) showed that the activation energy $\mathrm{E}_{\alpha}$ was 41.71 $\mathrm{kJ} / \mathrm{mol}$, and preexponential factor A was $1.85 \times 10^{3} \mathrm{~s}^{-1}$.

The activation energy, $\mathrm{E}_{\alpha}$, could be thought as the amount of energy that have to be supplied to the reactants to get them to react with each other. Preexponential factor A was related to the number of collisions occurring in the chemical reaction that led to the formation of products from reactants. The results in Table 2 showed that lignin methylsulfonation need relatively high energy and thus need to supply the heating for reaction to occur.

In the kinetics study of base-catalyzed condensation reactions of lignin model compounds, the methylol group on the $5^{\text {th }}$ - position of lignin model compounds was activated to a greater extent by a propyl side chain, rather than by a methyl substituent. Since lignin was a macromolecule, it could diffuse slowly and the opportunity for collisions between reactive groups in lignin methylsulfonation, was lower. Therefore, the preexponential factor A was relatively low [4].

The reaction rate constant was higher at higher temperatures. It suggested that lignin methylsulfonation should be faster at higher temperatures. follows:

After all, the kinetic equation derived from isothermal DSC analysis could be described as

$$
\frac{\mathrm{d} \alpha}{\mathrm{dt}}=1.85 \times 10^{3} \exp \left(-\frac{5017}{\mathrm{~T}}\right)(1-\alpha)^{0,21}
$$




\section{CONCLUSION}

In this work, the reaction kinetics of lignin methylsulfonation was investigated by isothermal DSC, and the kinetic parameters have been obtained. The apparent activation energy $\left(E_{\alpha}\right)$ was found to be $E_{\alpha}=41.71 \mathrm{~kJ} / \mathrm{mol}$, and preexponential factor $A$ was $1.85 \times 10^{3} \mathrm{~s}^{-1}$.

\section{REFERENCES}

1. Drews M. J., Barr M., and Williams M. - A Kinetic Study of the SCWO of a Sulfonated Lignin Waste Stream, Ind. Eng. Chem. Res. 39 (2000) 4784-4793.

2. Inwood T. John Paul William - Sulfonation of kraft lignin to water soluble value added products - Thesis of Master of Science in Environmental Engineering, Lakehead University, 2014.

3. Nguyen Truong Giang, Tran Trung Kien, Nguyen Thi Hoa, Pham Vam Thiem - A new synthesis process of lignosulfonate using lignin recovered from black liquour of pulp and paper mills, Vietnam Journal of Science and Technology 54 (4B) (2016) 1-10.

4. Gardner D. J. and Moginnis G. D. - Comparison of the reaction rates of the alkali catalyzed addition of formaldehyde to phenol and selected lignins, J. Wood Chem. Technol. 8 (1988) 261.

5. Peng W., Riedl B. and Barry A. O. - Study on the Kinetics of Lignin Methylolation, Journal of Applied Polymer Scienc 48 (1993) 1757-1763.

6. Alonsoa M.V., Oliet M., Garcia J., Rodriguez F., Echeverna J. - Gelation and isoconversional kinetic analysis of lignin-phenol-formaldehyde resol resins methylsulfonation, Chemical Engineering Journal 122 (2006) 159-166.

7. Mehdi Ghaffari, Morteza Ehsani, Hossein Ali Khonakdar, Guy Van Assche, Herman Terryn - The kinetic analysis of isothermal reaction reaction of an epoxy resin-glassflake nanocomposite, Thermochimica Acta 549 (2012) 81- 86.

8. Sergey Vyazovkin, Alan K. Burnham, José M. Criado, Luis A. Pérez-Maqueda, Crisan Popescu, Nicolas Sbirrazzuoli - ICTAC Kinetics Committee recommendations for performing kinetic computations on thermal analysis data, Thermochimica Acta $\mathbf{5 2 0}$ (2011) 1-19.

9. Lei Y., Wu Q., Lian K. - Cure Kinetics of Aqueous Phenol-Formaldehyde Resins Used for Oriented Strandboard Manufacturing: Analytical Technique, Journal of Applied Polymer Science 100 (2006) 1642-1650.

10. Thermal Safety of Chemical Processes: Risk Assessment and Process Design, Chapter 12. Autocatalytic Reactions, Francis Stoessel, 2008 Wiley-VCH Verlag GmbH \& Co. KGaA, p. 314 . 